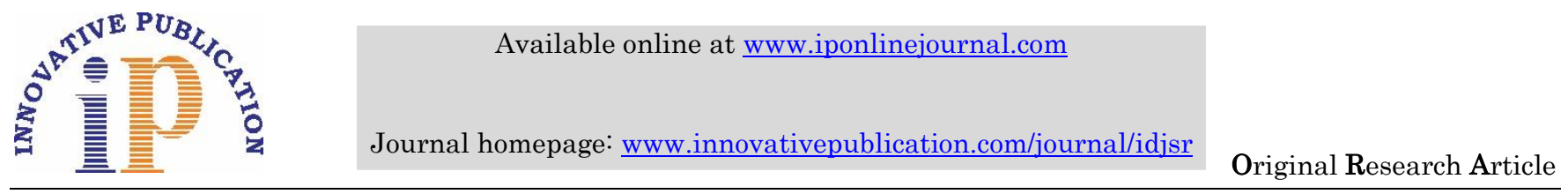

\title{
Dental Students knowledge in diagnosing orthodontic problems in Riyadh city, Saudi Arabia
}

\author{
Eman Jameel Fatani, ${ }^{1, *}$, Yasmeen Jamaledin Hassanain ${ }^{2}$, Sahar Hussein AlTuraifi ${ }^{3}$, Waad AlGhamdi ${ }^{4}$, Masheel \\ Hamed AlNasser ${ }^{5}$, Alzahraa AliAlnahwi ${ }^{6}$, Zainab Ali AlSaeed ${ }^{7}$ \\ ${ }^{1}$ Consultant Orthodontist/Lecturer, ${ }^{2-7}$ Inter, ${ }^{1}$ Dept. of Orthodontics, Riyadh Elm University, Riyadh, KSA
}

\begin{abstract}
Objective: To investigate the ability of undergraduate senior dental students in diagnosing orthodontic problems and to evaluate the clinical approach of these students toward a patient displaying such problems.

Materials and Methods: Study was started after the approval by the Institutional Review Board of Riyadh Elm University $\mathrm{RC} / \mathrm{IRB} / 2018 / 1323$ with registration number registration number FUGRP/2018/65. The sample consisted of 786 dental students at a private dental university in Riyadh city, and were assessed by questionnaires with closed questions. They were presented with photographs of patients with different types of malocclusions.

Results: It was found that level 11 students showed better knowledge in diagnosing the different malocclusions presented in each case. With regards to gender, the female students were significantly more likely to diagnose the need for orthodontic treatment than male students. There was a significant difference between the levels on the interpretation of who could provide the orthodontic treatment. But respondents found it difficult to determine the ideal moment to start orthodontic treatment.

Conclusion: On completion of their undergraduate courses, students encounter difficulties in diagnosing various orthodontic problems and even find it hard to articulate ideas about a basic treatment protocol to correct this malocclusion.
\end{abstract}

Keywords: Diagnosis, Malocclusion, Orthodontic referral.

\section{Introduction}

With increasing need of diagnosing dental malocclusions at an early stage by the general dentist and the ability to refer the child at the right age either to an orthodontist or carry out themselves the necessary interceptive treatment, there is a major role on dental institutes to provide the knowledge to the undergraduate dental students and in most dental curriculums the topic of orthodontic is limited, this raises the concern and is this sufficient to enable them as dentists to determine orthodontic treatment need and more importantly the correct intervention timing. These required competencies such as orthodontic assessment, diagnosis, prevention, and health promotion need to be assessed at different levels of their program as the exposure time is limited thus can act as a blueprint to assess the learning outcome. Literature is lacking in measuring the ability of general dental practitioners and senior dental students to diagnose orthodontic need of young patients and to make an informed decision about the proper timing of treatment. ${ }^{1}$

Association for Dental Education in Europe (ADEE) states that dental graduates should be able to handle "all forms of orthodontic emergency, including referral when necessary'. Thus dental students should be exposed to orthodontic problems so as to build up knowledge, proficiency, and confidence in managing orthodontic cases. The inadequate published literature in the meadow, however, suggests that student's self-confidence in dealing with orthodontic problems is low. In a study of the vocational dental practitioner's in their first year of employment noticed that $60 \%$ of practitioners were not confident in handling an orthodontic patient. To boot, $72 \%$ of them revealed they were not confident with the use of fixed orthodontic appliances and 55\% of them stated that they were not certain with the use of removable appliances. ${ }^{3}$

Therefore, it is imperative for dentists to acquire a level of confidence that will permit them to effectively manage orthodontic patients. Understanding the cause why there is low confidence in students in identifying orthodontic problem would provide valuable information to feed back into teaching programs in sequence for these problems to be sermonized. Enhancement in the learning experiences of dental students will eventually help both the practitioner once trained and the clinical care that is rendered to the patients. ${ }^{2}$ Therefore, aims of this study were to: Assess the ability of undergraduate students in diagnosing orthodontic problems and to evaluate the clinical approach of these students toward a patient displaying such problems.

\section{Materials and Methods}

Approval of this study was granted by the Institutional Review Board of Riyadh Elm University RC/IRB/2018/1323 with registration number registration number FUGRP/2018/65. A Web-based survey (Survey Monkey) was sent to dental students' $9^{\text {th }}-12^{\text {th }}$ level and interns of Riyadh Elm University. The target was 1000 responses; the compliance was 786responses. Four intra oral frontal views photographs were used representing different occlusions of children in various dental stages and

*Corresponding Author: Eman Jameel Fatani, Dept. of Orthodontics, Riyadh Elm University, Riyadh, KSA

Email address: mypublicationdev@ gmail.com

http://doi.org/10.18231/j.idjsr.2019.013 
malocclusions (1. Pseudo class III due to occlusal interferences, 2. Class III malocclusion, 3. Ugly Duckling stage (normal physiological developmental stage) and 4. Class I malocclusion) with 3 questions (Table 1).

Responses were checked for completeness, summarized and analyzed. The data was correlated to both gender and educational level. Chi-squared test was used to evaluate significant differences between the groups for each question.

\section{Results}

Demographic data showed that a total of 786 students participated in the study male $(n=285$ and female $(n=501)$ (Table 2). Regarding the ability to identify the cases that need orthodontic treatment level 11 students showed better knowledge in diagnosing the different malocclusions presented in each case with regards to gender the female students were significantly more likely to diagnose the need for orthodontic treatment than male students. There was a significant difference between the levels on the interpretation of who could provide the orthodontic treatment. Results indicated that Case 1 could be treated by a general dentist whereas Case 2-4 could not be treated by a general dentist. There was no significant difference seen between Cases 1-3. Case 4 when assessed showed no significance $(p>0.05)$ therefore patients could not be managed by a general dentist (Table 3,4). There was a significant difference between the levels on the interpretation of who could provide dental treatment. The level 11 students were significantly more accurate than their counterparts in other levels at being able to predict who should provide the orthodontic treatment.

No significant difference between levels on when to treat patients $(\mathrm{p}<0.05)$ (Table 5). A comprehensive orthodontic course did improve the overall strength of the relationship between the two variables that is when to treat patients and the level when the questionnaire was administered.

$69.7 \%$ of males and $83.9 \%$ of females agreed that permanent dentition was the appropriate stage to treat Case 4. Males and females both agreed that Case 3 could be treated at the mixed dentition stage at $58.9 \%$ and $83.7 \%$ respectively. Again, there was no seen difference between males and females regarding the stage of treatment. Primary dentition treatment as the best stage was observed in $61.6 \%$ of males and $81.1 \%$ of females. Case 1 showed a no significant difference between males and females; although the majority of males agreed that primary dentition was the best stage whereas female students did not agree answering that mixed dentition was a better option (Table 6). For all four cases, the females were significantly more likely to feel the case needed orthodontic treatment than the males.

Table 1: Questions

\begin{tabular}{|c|c|c|}
\hline \multicolumn{3}{|c|}{ 1. Does this patient need orthodontic treatment? } \\
\hline \multicolumn{2}{|c|}{ Yes } & No \\
\hline \multicolumn{3}{|c|}{ 2. Can this patient be treated by a general dentist or an orthodontist? } \\
\hline \multicolumn{2}{|c|}{ General Dentist } & Orthodontist \\
\hline \multicolumn{3}{|c|}{ 3. What is the best dental stage to treat this case ? } \\
\hline Primary dentition & Mixed dentition & Permanent dentition \\
\hline
\end{tabular}

Table 2: Demographic data

\begin{tabular}{|c|c|c|c|c|c|}
\hline \multicolumn{2}{|c|}{} & \multicolumn{4}{c|}{ Gender } \\
\cline { 3 - 6 } \multicolumn{2}{c|}{} & \multicolumn{2}{|c|}{ Male } & \multicolumn{2}{c|}{ Female } \\
\cline { 3 - 6 } \multicolumn{2}{|c|}{} & Count & $\%$ & Count & $\%$ \\
\hline \multirow{3}{*}{ Level } & Intern & 50 & $17.5 \%$ & 52 & $10.4 \%$ \\
\cline { 2 - 6 } & Level 9 & 58 & $20.4 \%$ & 44 & $8.8 \%$ \\
\cline { 2 - 6 } & Level 10 & 67 & $23.5 \%$ & 47 & $9.4 \%$ \\
\cline { 2 - 6 } & Level 11 & 64 & $22.5 \%$ & 286 & $57.1 \%$ \\
\cline { 2 - 6 } & Level 12 & 46 & $16.1 \%$ & 72 & $14.4 \%$ \\
\hline
\end{tabular}

Table 3: Need for orthodontic treatment comparison according to level

\begin{tabular}{|c|c|c|c|c|c|c|c|c|c|c|c|c|c|c|}
\hline & \multicolumn{13}{|c|}{ Level } \\
\hline & & \multicolumn{2}{|c|}{ Intern } & \multicolumn{2}{|c|}{ Level 9} & \multicolumn{2}{|c|}{ Level 10} & \multicolumn{2}{|c|}{ Level 11} & \multicolumn{2}{|c|}{ Level 12} & \multirow{2}{*}{$X^{2}$} & \multirow{2}{*}{ df } & \multirow{2}{*}{$\mathrm{p}$} \\
\hline & & Count & $\%$ & Count & $\%$ & Count & $\%$ & Count & $\%$ & Count & $\%$ & & & \\
\hline \multirow{2}{*}{ Case 1} & Yes & 73 & $71.6 \%$ & 63 & $61.8 \%$ & 70 & $61.9 \%$ & 329 & $93.7 \%$ & 93 & $77.5 \%$ & \multirow{2}{*}{89.522} & \multirow{2}{*}{4} & \multirow{2}{*}{$<0.001$} \\
\hline & No & 29 & $28.4 \%$ & 39 & $38.2 \%$ & 43 & $38.1 \%$ & 22 & $6.3 \%$ & 27 & $22.5 \%$ & & & \\
\hline \multirow{2}{*}{ Case 2} & Yes & 78 & $77.2 \%$ & 81 & $79.4 \%$ & 81 & $71.7 \%$ & 336 & $95.7 \%$ & 100 & $84.0 \%$ & \multirow{2}{*}{57.354} & \multirow{2}{*}{4} & \multirow{2}{*}{$<0.001$} \\
\hline & No & 23 & $22.8 \%$ & 21 & $20.6 \%$ & 32 & $28.3 \%$ & 15 & $4.3 \%$ & 19 & $16.0 \%$ & & & \\
\hline \multirow{2}{*}{ Case 3} & Yes & 51 & $51.0 \%$ & 49 & $48.0 \%$ & 52 & $45.6 \%$ & 39 & $11.1 \%$ & 75 & $63.0 \%$ & \multirow{2}{*}{155.657} & \multirow{2}{*}{4} & \multirow{2}{*}{$<0.001$} \\
\hline & No & 49 & $49.0 \%$ & 53 & $52.0 \%$ & 62 & $54.4 \%$ & 312 & $88.9 \%$ & 44 & $37.0 \%$ & & & \\
\hline \multirow{2}{*}{ Case 4} & Yes & 88 & $88.9 \%$ & 97 & $95.1 \%$ & 92 & $81.4 \%$ & 335 & $95.4 \%$ & 106 & $88.3 \%$ & \multirow{2}{*}{25.801} & \multirow{2}{*}{4} & \multirow{2}{*}{$<0.001$} \\
\hline & No & 11 & $11.1 \%$ & 5 & $4.9 \%$ & 21 & $18.6 \%$ & 16 & $4.6 \%$ & 14 & $11.7 \%$ & & & \\
\hline
\end{tabular}


Table 4: Can a general dentist provide orthodontic treatment, comparison across levels on whether a general dentist can provide orthodontic treatment?

\begin{tabular}{|c|c|c|c|c|c|c|c|c|c|c|c|c|c|c|}
\hline & \multicolumn{13}{|c|}{ Level } \\
\hline & & \multicolumn{2}{|c|}{ Intern } & \multicolumn{2}{|c|}{ Level 9} & \multicolumn{2}{|c|}{ Level 10} & \multicolumn{2}{|c|}{ Level 11} & \multicolumn{2}{|c|}{ Level 12} & \multirow[t]{2}{*}{$\mathrm{X}^{2}$} & \multirow[t]{2}{*}{ df } & \multirow[t]{2}{*}{$\mathrm{p}$} \\
\hline & & Count & $\%$ & Count & $\%$ & Count & $\%$ & Count & $\%$ & Count & $\%$ & & & \\
\hline \multirow[t]{2}{*}{ Case 1} & Yes & 57 & $67.1 \%$ & 48 & $64.0 \%$ & 54 & $64.3 \%$ & 314 & $92.6 \%$ & 68 & $65.4 \%$ & \multirow[t]{2}{*}{77.293} & \multirow[t]{2}{*}{4} & \multirow[t]{2}{*}{$<0.001$} \\
\hline & No & 28 & $32.9 \%$ & 27 & $36.0 \%$ & 30 & $35.7 \%$ & 25 & $7.4 \%$ & 36 & $34.6 \%$ & & & \\
\hline \multirow[t]{2}{*}{ Case 2} & Yes & 40 & $45.5 \%$ & 39 & $44.8 \%$ & 48 & $52.2 \%$ & 49 & $14.4 \%$ & 47 & $43.1 \%$ & \multirow[t]{2}{*}{87.071} & \multirow[t]{2}{*}{4} & \multirow[t]{2}{*}{$<0.001$} \\
\hline & No & 48 & $54.5 \%$ & 48 & $55.2 \%$ & 44 & $47.8 \%$ & 292 & $85.6 \%$ & 62 & $56.9 \%$ & & & \\
\hline \multirow[t]{2}{*}{ Case 3} & Yes & 18 & $29.0 \%$ & 14 & $25.5 \%$ & 13 & $20.6 \%$ & 264 & $87.7 \%$ & 18 & $20.9 \%$ & \multirow{2}{*}{$\begin{array}{c}238.41 \\
4\end{array}$} & \multirow[t]{2}{*}{4} & \multirow[t]{2}{*}{$<0.001$} \\
\hline & No & 44 & $71.0 \%$ & 41 & $74.5 \%$ & 50 & $79.4 \%$ & 37 & $12.3 \%$ & 68 & $79.1 \%$ & & & \\
\hline \multirow[t]{2}{*}{ Case 4} & Yes & 16 & $16.7 \%$ & 9 & $8.9 \%$ & 16 & $16.3 \%$ & 19 & $5.5 \%$ & 19 & $16.5 \%$ & \multirow[t]{2}{*}{21.569} & \multirow[t]{2}{*}{4} & \multirow[t]{2}{*}{$<0.001$} \\
\hline & No & 80 & $83.3 \%$ & 92 & $91.1 \%$ & 82 & $83.7 \%$ & 328 & $94.5 \%$ & 96 & $83.5 \%$ & & & \\
\hline
\end{tabular}

Table 5: Comparison among levels on when to treat the patients

\begin{tabular}{|c|c|c|c|c|c|c|c|c|c|c|c|c|c|c|}
\hline & \multicolumn{13}{|c|}{ Level } \\
\hline & & \multicolumn{2}{|c|}{ Intern } & \multicolumn{2}{|c|}{ Level 9} & \multicolumn{2}{|c|}{ Level 10} & \multicolumn{2}{|c|}{ Level 11} & \multicolumn{2}{|c|}{ Level 12} & \multirow[t]{2}{*}{$\mathrm{X} 2$} & \multirow[t]{2}{*}{$\mathrm{df}$} & \multirow[t]{2}{*}{$\mathrm{p}$} \\
\hline & & Count & $\%$ & Count & $\%$ & Count & $\%$ & Count & $\%$ & Count & $\%$ & & & \\
\hline \multirow{3}{*}{$\begin{array}{c}\text { Case } \\
1\end{array}$} & Primary Dentition & 39 & $44.8 \%$ & 61 & $76.3 \%$ & 56 & $65.9 \%$ & 76 & $22.2 \%$ & 50 & $46.7 \%$ & \multirow{3}{*}{$\begin{array}{l}148 . \\
177\end{array}$} & \multirow[t]{3}{*}{8} & \multirow{3}{*}{$\begin{array}{l}<0 . \\
001\end{array}$} \\
\hline & Mixed Dentition & 41 & $47.1 \%$ & 14 & $17.5 \%$ & 21 & $24.7 \%$ & 256 & $74.9 \%$ & 44 & $41.1 \%$ & & & \\
\hline & Permanent Dentition & 7 & $8.0 \%$ & 5 & $6.3 \%$ & 8 & $9.4 \%$ & 10 & $2.9 \%$ & 13 & $12.1 \%$ & & & \\
\hline \multirow{3}{*}{$\begin{array}{c}\text { Case } \\
2\end{array}$} & Primary Dentition & 58 & $65.9 \%$ & 42 & $47.2 \%$ & 56 & $61.5 \%$ & 314 & $92.1 \%$ & 66 & $60.0 \%$ & \multirow{3}{*}{$\begin{array}{l}138 . \\
841\end{array}$} & \multirow[t]{3}{*}{8} & \multirow{3}{*}{$\begin{array}{l}<0 \text {. } \\
001\end{array}$} \\
\hline & Mixed Dentition & 25 & $28.4 \%$ & 43 & $48.3 \%$ & 30 & $33.0 \%$ & 22 & $6.5 \%$ & 27 & $24.5 \%$ & & & \\
\hline & Permanent Dentition & 5 & $5.7 \%$ & 4 & $4.5 \%$ & 5 & $5.5 \%$ & 5 & $1.5 \%$ & 17 & $15.5 \%$ & & & \\
\hline \multirow{3}{*}{$\begin{array}{c}\text { Case } \\
3\end{array}$} & Primary Dentition & 8 & $10.7 \%$ & 8 & $12.5 \%$ & 15 & $18.1 \%$ & 8 & $2.6 \%$ & 20 & $19.2 \%$ & \multirow{3}{*}{$\begin{array}{l}101 . \\
450\end{array}$} & \multirow[t]{3}{*}{8} & \multirow{3}{*}{$\begin{array}{l}<0 . \\
001\end{array}$} \\
\hline & Mixed Dentition & 49 & $65.3 \%$ & 39 & $60.9 \%$ & 50 & $60.2 \%$ & 290 & $93.5 \%$ & 60 & $57.7 \%$ & & & \\
\hline & Permanent Dentition & 18 & $24.0 \%$ & 17 & $26.6 \%$ & 18 & $21.7 \%$ & 12 & $3.9 \%$ & 24 & $23.1 \%$ & & & \\
\hline \multirow{3}{*}{$\begin{array}{c}\text { Case } \\
4\end{array}$} & Primary Dentition & 8 & $8.3 \%$ & 5 & $5.0 \%$ & 8 & $8.2 \%$ & 9 & $2.6 \%$ & 11 & $9.5 \%$ & \multirow{3}{*}{$\begin{array}{c}69.7 \\
77\end{array}$} & \multirow[t]{3}{*}{8} & \multirow{3}{*}{$\begin{array}{l}<0 . \\
001\end{array}$} \\
\hline & Mixed Dentition & 25 & $26.0 \%$ & 23 & $23.0 \%$ & 20 & $20.4 \%$ & 18 & $5.2 \%$ & 30 & $25.9 \%$ & & & \\
\hline & Permanent Dentition & 63 & $65.6 \%$ & 72 & $72.0 \%$ & 70 & $71.4 \%$ & 319 & $92.2 \%$ & 75 & $64.7 \%$ & & & \\
\hline
\end{tabular}

Table 6: Effect of gender

\begin{tabular}{|c|c|c|c|c|c|c|c|c|}
\hline \multirow{3}{*}{\multicolumn{2}{|c|}{$\begin{array}{l}\text { Need for orthodontic } \\
\text { treatment }\end{array}$}} & \multicolumn{7}{|c|}{ Gender } \\
\hline & & \multicolumn{2}{|c|}{ Male } & \multicolumn{2}{|c|}{ Female } & \multirow[t]{2}{*}{$\mathrm{X}^{2}$} & \multirow[t]{2}{*}{$\mathrm{df}$} & \multirow{2}{*}{$\mathrm{p}$} \\
\hline & & Count & $\%$ & Count & $\%$ & & & \\
\hline \multirow[t]{2}{*}{ Case 1} & Yes & 194 & $68.1 \%$ & 433 & $86.1 \%$ & \multirow[t]{2}{*}{36.311} & \multirow[t]{2}{*}{1} & \multirow[t]{2}{*}{$<0.001$} \\
\hline & No & 91 & $31.9 \%$ & 70 & $13.9 \%$ & & & \\
\hline \multirow[t]{2}{*}{ Case 2} & Yes & 216 & $75.8 \%$ & 459 & $91.6 \%$ & \multirow[t]{2}{*}{37.522} & \multirow[t]{2}{*}{1} & \multirow[t]{2}{*}{$<0.001$} \\
\hline & No & 69 & $24.2 \%$ & 42 & $8.4 \%$ & & & \\
\hline \multirow[t]{2}{*}{ Case 3} & Yes & 120 & $42.1 \%$ & 146 & $29.2 \%$ & \multirow[t]{2}{*}{13.495} & \multirow[t]{2}{*}{1} & \multirow[t]{2}{*}{$<0.001$} \\
\hline & No & 165 & $57.9 \%$ & 354 & $70.8 \%$ & & & \\
\hline \multirow[t]{2}{*}{ Case 4} & Yes & 247 & $86.7 \%$ & 471 & $94.2 \%$ & \multirow[t]{2}{*}{13.197} & \multirow[t]{2}{*}{1} & \multirow[t]{2}{*}{$<0.001$} \\
\hline & No & 38 & $13.3 \%$ & 29 & $5.8 \%$ & & & \\
\hline \multirow{3}{*}{\multicolumn{2}{|c|}{$\begin{array}{l}\text { Can this patient be } \\
\text { managed by a general } \\
\text { dentist }\end{array}$}} & \multicolumn{7}{|c|}{ Gender } \\
\hline & & \multicolumn{2}{|c|}{ Male } & \multicolumn{2}{|c|}{ Female } & \multirow[t]{2}{*}{$\mathrm{X}^{2}$} & \multirow[t]{2}{*}{ df } & \multirow[t]{2}{*}{$\mathrm{p}$} \\
\hline & & Count & $\%$ & Count & $\%$ & & & \\
\hline \multirow[t]{2}{*}{ Case 1} & Yes & 138 & $63.6 \%$ & 402 & $85.7 \%$ & \multirow[t]{2}{*}{43.328} & 1 & $<0.001$ \\
\hline & No & 79 & $36.4 \%$ & 67 & $14.3 \%$ & & & \\
\hline Case 2 & Yes & 108 & $45.8 \%$ & 115 & $23.9 \%$ & 35.287 & 1 & $<0.001$ \\
\hline & No & 128 & $54.2 \%$ & 366 & $76.1 \%$ & & & \\
\hline Case 3 & Yes & 43 & $30.1 \%$ & 285 & $67.4 \%$ & 61.038 & 1 & $<0.001$ \\
\hline & No & 100 & $69.9 \%$ & 138 & $32.6 \%$ & & & \\
\hline Case 4 & Yes & 34 & $12.8 \%$ & 46 & $9.3 \%$ & 2.236 & 1 & $<0.001$ \\
\hline & No & 231 & $87.2 \%$ & 447 & $90.7 \%$ & & & \\
\hline When & treat the & & & & Genc & & & \\
\hline patients & & & & & & & & \\
\hline & & Count & $\%$ & Count & $\%$ & & & \\
\hline Case 1 & Primary & 152 & $66.7 \%$ & 129 & $27.3 \%$ & 111.063 & 2 & $<0.001$ \\
\hline
\end{tabular}




\begin{tabular}{|c|c|c|c|c|c|c|c|c|}
\hline & Mixed & 58 & $25.4 \%$ & 318 & $67.2 \%$ & & & \\
\hline & Permanent & 18 & $7.9 \%$ & 26 & $5.5 \%$ & & & \\
\hline \multirow[t]{3}{*}{ Case 2} & Primary & 146 & $61.6 \%$ & 390 & $81.1 \%$ & \multirow[t]{3}{*}{31.872} & \multirow[t]{3}{*}{2} & \multirow[t]{3}{*}{$<0.001$} \\
\hline & Mixed & 74 & $31.2 \%$ & 73 & $15.2 \%$ & & & \\
\hline & Permanent & 17 & $7.2 \%$ & 18 & $3.7 \%$ & & & \\
\hline \multirow[t]{3}{*}{ Case 3} & Primary & 33 & $18.9 \%$ & 26 & $5.7 \%$ & \multirow[t]{3}{*}{46.146} & \multirow[t]{3}{*}{2} & \multirow[t]{3}{*}{$<0.001$} \\
\hline & Mixed & 103 & $58.9 \%$ & 384 & $83.7 \%$ & & & \\
\hline & Permanent & 39 & $22.3 \%$ & 49 & $10.7 \%$ & & & \\
\hline \multirow[t]{3}{*}{ Case 4} & Primary & 23 & $8.7 \%$ & 19 & $3.9 \%$ & \multirow[t]{3}{*}{21.492} & \multirow[t]{3}{*}{2} & \multirow[t]{3}{*}{$<0.001$} \\
\hline & Mixed & 57 & $21.6 \%$ & 60 & $12.2 \%$ & & & \\
\hline & Permanent & 184 & $69.7 \%$ & 413 & $83.9 \%$ & & & \\
\hline
\end{tabular}

\section{Discussion}

In our dental undergraduate curriculum, dental graduates should be able to recognize malocclusions, educate parents about what is the proper age for orthodontic treatment for different malocclusions and perform simple interceptive measures. Dental students should, therefore, be exposed to orthodontic cases in order to develop knowledge, competence, and confidence in managing orthodontic emergencies or referring these patients at the right age to an Orthodontist. The limited published literature in the field, however, suggests that student's confidence in dealing with orthodontic diagnosis is low. Ultimately the data from this study can assist universities in evaluating the learning outcomes and competence of the graduates in identifying various malocclusions and provide them with the knowledge and competency to carry out simple interventions. ${ }^{4}$

The intention of the survey was to check whether or not some fundamental diagnostic concepts had been engrossed by undergraduate students, who had previously attended the course in orthodontics. These upcoming dental professionals should be proficient in identifying dental occlusion problems in their patients and referring them for orthodontic treatment during their clinical career. In 1980, a Curricular Guide for Orthodontics was developed by The American Association of Dental schools, with the intent of establishing the content of orthodontic education programs, together with enough information to facilitate students to identify and take action in the presence of malocclusions by distinguishing cases of interceptive orthodontics from other cases which needs referral to orthodontists. ${ }^{1}$

Heath et al assessed the perceptions of orthodontic case complexity among dental students and general practitioners. Their results showed that most dental professionals believe that their undergraduate orthodontic training was inadequate. Noble et al. in 2009 found that the amount of orthodontic information given in the undergraduate curriculum in dental schools was that, $60 \%$ of the orthodontic residents in Canada had the right amount of orthodontics exposure in the dental school, while $36 \%$ of the residents did not have enough information. In regards to gender, the female students displayed better ability to diagnose malocclusions and the proper timing of treatment. ${ }^{5}$ This was noted in the current study where the female students were significantly more likely to diagnose the need for orthodontic treatment than male students. But in the contrary, study done by Sastri et al, revealed that male dental practitioners had more positive attitude and knowledge than female practitioners, toward principles and practice of orthodontic treatment. ${ }^{6}$ This was in line with research by Alnusayri et al which revealed the similar results. ${ }^{7}$

The truly imperative responsibility of the general dentist is in the identification of malocclusion and treats wherever possible in the initiation of simple interceptive procedures. Nevertheless, it was noticed that more than $50 \%$ of general dental practitioners refer the patients to specialists and some practitioners appear to refer with little thought. ${ }^{8}$ Steven Shaw noticed an important observation from his research that students with higher knowledge of aligner were more expected to refer orthodontic patients to a specialist. Which indicated that students were aware of its limitations they are more likely to refer orthodontic cases instead of trying to treat such patients. ${ }^{9}$ In a study done on students of King Abdul Aziz University in Jeddah, Saudi Arabia most of the students above $70 \%$ were confident to diagnose orthodontic problems and are able to refer the patient to the orthodontist. This was in agreement with our results and in contrast to the findings of Noble and colleagues. ${ }^{10}$ In a study shortfall in the training of general practitioners are noticed not only in diagnosing malocclusion but as well in recognizing the favorable time for treatment of various malocclusions and referral to orthodontists. ${ }^{11}$ To support this, one research revealed that a greater percentage of general dental practitioner's orthodontic treatment plans were found to be improper when assessed by orthodontists. ${ }^{8}$

In the current study when all the students asked regarding the age to start the orthodontic therapy, depending up on the cases given there was no significant difference between levels was noted. But in the study by Alnusayri et al, $80.31 \%$ of the participants replied that treatment can be started at any age. ${ }^{7}$ One questionnaire study showed that most of the dental students did not have sufficient knowledge to decide the most favorable stage to initiate the treatment. It was quite simple for them to diagnose Class I patient $(87.59 \%)$, as well as the increased overjet (79.6\%) and diastema (81.7\%) and overbite (28.9\%), and only a small percentage of the participants contemplated it as 
normal during mixed dentition. About $10.1 \%$ considered that there was no need for orthodontic treatment, as the occlusion was attuned with the normal development. ${ }^{12}$ Similarly, a study by Canavarro et al found that students had intricacy in accurately identifying Angle Class II, Division 1 malocclusion, since merely half of the respondents did so in the approved manner. ${ }^{1}$ This revealed that majority of the students were unsuccessful to recognize that in the "ugly duckling" stage these appearances are quite natural to normal development and they referred such patients to an orthodontist, which might result in undesirable treatment. In contrary, a survey of dentists with more clinical experience by Fleming et al reported more positive findings with $60 \%$ of participants stated that they were confident in treating orthodontic cases. ${ }^{13}$

In the current study, the vast preponderance of respondents could effortlessly identify the existence of dental midline diastema, the presence of increased overjet, overbite and crossbite, since all these traits are perceptible in the anterior region of the dental arches. The results of this study showed that the majority of the responders were able to identify the cases that had malocclusions except for the ugly duckling stage where $89 \%$ of level 11 students answered correctly. It was noticed that the level 11 students were significantly more accurate than their counterparts in other levels at being able to predict who should provide the orthodontic treatment. This was in line with the study by Canavarro since the majority (95\%) of the students referred the patient to an orthodontist. ${ }^{1}$ In a study by Rock et al, students possessed excellent levels of basic orthodontic knowledge but failed to utilize that knowledge to clinical situations. ${ }^{8}$ These findings lead to a mirror image about curriculum content and teaching methodology of UG orthodontic courses given their incapability to succeed future clinicians to recognize a malocclusion often seen in dental practice. ${ }^{1}$

It should be emphasized that patients with the orthodontic problem will be initially seen by a general dentist or pedodontist and consequently for further clarification about the condition to the patient or parents, they are the ones who refer patients to an orthodontist. Therefore, general dental practitioners should be aware with the most appropriate stage to instigate treatment, which is preferable during a pubertal growth spurt, when correction can be done with greater efficacy and efficiency. ${ }^{1}$

In light of the results, it is recommended that more comprehensive studies should be carried out in order to authenticate the need to amend the content of UG orthodontics courses in the universities of Riyadh, Saudi Arabia. Educating the students on proper diagnosis, and the establishment of treatment plans should take preference over the fabrication of orthodontic appliances.

\section{Conclusion}

It appears that the Undergraduate programs need more exposure to the diagnosis of malocclusions and clinical attachments. A greater amount of clinical time should be dedicated so that students have more experience and exposure in what they feel least confident in the undertaking. On graduation, new dentists need the skill to be able to target their 'weak' areas through training. Results support the view that undergraduate orthodontic training should focus on diagnosis and recognition of problems rather than providing limited exposure to treatment techniques.

\section{Acknowledgment}

I would like to extend my sincere thanks to Akanksha Rao, Research Assistant, Riyadh Elm University, Olaya, Riyadh, $\mathrm{KSA}$, for encouragement and insightful assistances.

\section{Conflict of Interest}

None.

\section{References}

1. Canavarro C, Miguel JAM, Quintão CCA, Torres MdFM, Ferreira JdPM, Brunharo IHVP et al. Assessment of the orthodontic knowledge demonstrated by dental school undergraduates: recognizing the key features of Angle Class II, Division 1 malocclusion. Dent Press J Orthod 2012;17(1):5261.

2. Jones K, Popat H, Johnson IG. Dental students' experiences of treating orthodontic emergencies-a qualitative assessment of student reflections. Eur J Dent Educ 2016;20(3):156-60.

3. Patel J, Fox K, Grieveson B, Youngson CC. Undergraduate training as preparation for vocational training in England: a survey of vocational dental practitioners' and their trainers' views. Br Dent J. 2006;201(s5):9.

4. Bearn D, Chadwick S. Problem-based learning in postgraduate dental education: a qualitative evaluation of students' experience of an orthodontic problem-based postgraduate programme. Eur J Dent Educ 2010;14(1):26-34.

5. Heath EM, English JD, Johnson CD, Swearingen EB, Akyalcin S. Perceptions of orthodontic case complexity among orthodontists, general practitioners, orthodontic residents, and dental students. Am J Orthod Dentofacial Orthop 2017;151(2):335-41.

6. Sastri MR, Tanpure VR, Palagi FB, Shinde SK, Ladhe K, Polepalle T et al. Study of the Knowledge and Attitude about Principles and Practices of Orthodontic Treatment among General Dental Practitioners and Non-orthodontic Specialties. J Intl Oral Health JIOH 2015;7(3):44.

7. Alnusayri MO, KuraymAlenazi KK, Patil SR, Aileni KR, Rao KA. Knowledge and attitude regarding principles and practices of orthodontic treatment among general dental practitioners and non-orthodontic specialists of Saudi Arabia: A preliminary study. J Res Med Dent Sci 2017;5(3):59-62.

8. Rock W, O'Brien K, Stephens C. Orthodontic teaching practice and undergraduate knowledge in British dental schools. $\mathrm{Br}$ Dent J 2002;192(6):347.

9. Shaw S. Knowledge of Dental Students with Respect to Orthodontic Diagnosis and Clear Aligner Therapy, University of Missouri--Kansas City; 2016.

10. Alsulaimani FF. Evaluation of Undergraduate Orthodontic Courses at the Faculty of Dentistry in King Abdulaziz University. J King Abdulaziz Univ-Med Sci 2013;20(4):57-67.

11. Jacobs R. Ten-year study of strategies for teaching clinical inference in predoctoral orthodontic education. J Dent Educ 1988;52(5):235-44.

12. Miguel JAM, Brunharo IP, Esperão PTG. Normal occlusion during mixed dentition: recognition of occlusal traits by dental students. Revista Dent Press de Ortodontia e Ortopedia Facial 2005;10(1):59-66. 
13. Fleming P, Dowling P. A survey of undergraduate orthodontic training and orthodontic practices by general dental practitioners. J Irish Dent Assoc 2005;51(2):68-72

How to cite this article: Fatani EJ, Hassanain YJ, AlTuraifi $\mathrm{SH}$, AlGhamdi W, AlNasser MH, AliAlnahwi A, AlSaeed ZA. Undergraduate knowledge in diagnosing orthodontic problems in Riyadh city, Saudi Arabia. Int J Comprehensive Adv Pharmacol 2019;4(3):50-5. 